\title{
Prognostic Factors Affecting Survival in Patients with Ovarian Cancer: A 5-Year Experience in an University Hospital
}

\author{
Gül PINAR ${ }^{1 *}$, Tevfik PINAR ${ }^{2 *}$, Ayşe DURUKAN ${ }^{3}$, Ali AYHAN ${ }^{3}$ \\ ${ }^{1}$ Yıldırım Beyazıt University, Faculty of Health Sciences, Department of Nursing \\ ${ }^{2}$ Hacettepe University, Institute of Public Health \\ ${ }^{3}$ Baskent University Ankara Hospital, GyneOncologic Clinic, Ankara, TURKEY
}

\begin{abstract}
The aim if this study is to explore the impact of the various prognostic factors on overall survival in women with ovarian cancer (OC). Patients diagnosed with gynecologic malignancy in Gynecology Clinic of Baskent University Medicine Faculty between 2010 and 2015 included to study. Patients with ovarian $(n=112)$ cancers examined retrospectively. Kaplan-Meier, Univariate and Multivariate Cox regression model were performed to estimate for associations of potential variables with survival factors. The mean patient age was 56.4 y, range $20-80$. The overall survival was $94.3 \%, 83.4 \%, 66.4 \%, 54.7 \%$ and $42.8 \%$ at $1,23,4$ and 5 years respectively (60.5 months, range 43-68). 3-year disease-free survival was 25.3\% (18.3 months, range 17-20). Multivariate analysis of patients indicated that stage, histology, grade, age at diagnosis, comorbidity, recurrence, BMI, menopausal status and regional distance were independent prognostic factors on survival $(p<0.05)$. In conclusion, these results will presents a framework to identify fundamental causes in survival for OC.
\end{abstract}

Keywords: Ovarian cancer, 5-year survival, Prognostic factors

\section{ÖZET}

Over Kanserli Hastalarda Sağkalımı Etkileyen Prognostik Faktörler: Bir Üniversite Hastanesinin 5 Yıllık Deneyimi

Bu çalışmanın amacı, over kanseri (OK) hastalarında sağkalımı etkileyen prognostik faktörleri araştırmaktır. Çalışmada, 2010 ile 2015 yılları arasında Başkent Üniversitesi Tıp Fakültesi Hastanesi Jine-Onkoloji Bölümü'nde tanı alan 112 over kanserli hasta retrospektif olarak incelenmiştir. Sağkalım süreleri hesaplanırken Kaplan-Meier metodu ve sağkalımı etkileyen faktörlerin ilişkisini kestirmek amacıyla Çok yönlü ve Tek yönlü Cox Regression modeli kullanılmıştır. Hastaların ortalama yaşı 56.4 (20-80)'dür. Genel

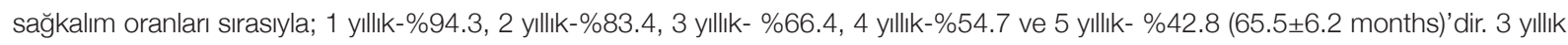
hastalıksız sağkalım oranı \%25.3 (18.3 3.94 months)'dir. Çok değişkenli analize göre, hastaların tanı aldığı yaş, BKi, komorbidite, evre, grade, histoloji, rekürrens, menopoz durumu ve bölgesel uzaklığın OK hastalarının sağkalımı üzerinde etkili olduğu bulundu ( $p<$ 0.05). Bu çalışmanın sonucunda elde edilen bulgular, OK sağkalımının temel nedenlerini belirlemede önemli bir çerçeve sunacaktır.

Anahtar Kelimeler: Over kanseri, 5 yıllık sağkalım, Prognostic faktörler

${ }^{*}=$ Formerly 


\section{INTRODUCTION}

Ovarian cancer (OC) is the deadliest gynecologic cancer worldwide, with nearly 225.000 new cases diagnosed each year and 140.000 deaths annually.Lifetime risk of OC in women is one in 71, and the risk of dying from the disease is 1 in $95 .{ }^{1}$ Based on GLOBOCAN estimates, the incidence and mortality of $\mathrm{OC}$ varies in different regions of the world; Scandinavian (14.9/100000), USA (13.3/100000), UK (11.7/100000), Russian Federation (11.3/100000), and Japan (4.8/100000). ${ }^{2}$ In Turkey (6.6/10000), OC is also a major health problem in women following breast cancer. This is higher than that of the previous reports in Turkey. ${ }^{3}$

Regrettably, identifying this disease is difficult. There is no routine, screening test to accurately and reliably detect $\mathrm{OC}$ in the general population so diagnosis of OC in the advanced stages leads to this cancer being considered as a fatal disease. Although the incidence and mortality of this disease is high, its prognostic factors are still not completely understood especially in low-income countries. ${ }^{4,5}$ In the literature, survival depends on many factors such as patient's family history, multiple comorbidities, postoperative complications, chemotherapy toxicities, increasing age, postmenopausal period, recurrence, presence of positive lymph nodes, advanced stage and grade, carcinosarcomas subtype, ascites, never having been pregnant and having never taken oral contraceptives, as well as lifestyle factors such as performance status, smoking and obesity. ${ }^{6-11}$

Statistics show that survival from all cancers in women was $64.2 \%$ while it was approximately $45.0 \%$ for OC globally and the 5-year survival rate has improved in OC by only 9\% since 1975 even in high-income countries. ${ }^{2}$ A 5-year survival rate is about $43 \%$ in Turkey (1970s-37\%, 1980s-40\%, and 2000s-45\%). ${ }^{3}$ Despite the recently improvements such as advances in the diagnosis, staging, and treatment of OC, and provided significant advancement of patients survival, major challenges related to the prognostic implications of its clinicpathologic characteristics remain controversial in the management of OC. Most women with OC are likely living with the disease rather than living cancer-free and some oncologists consider OC a chronic disease. ${ }^{9,12}$ Relatively, limited comprehensive national information describing clinical and nonclinical factors associated with survival is available in Turkish women with OC. Therefore, estimating survival is remarkable that provide an understanding of the disease course and better prognosis for OC.

\section{PATIENTS AND METHODS}

The aim of this study was to investigate determinant factors associated with survival of women with OC over the course of five years. The population of the study consisted of all patients with OC in years 2010-2015 who were actively followed-up and age 18 years or older were included at the Gynecologic Oncology Clinic, Faculty of Medicine, Baskent University Hospital $(n=112)$. Patients with unknown treatment data, or missing information were excluded. In addition, patients who survived less than 12 months after diagnosis were excluded to limit bias. Patients were scheduled for follow-up every two months in the first year, every three months during the second year and every six months thereafter. Follow-up data such as date of last visit and disease status at the time of the last contact were also noted. This study was conducted at a multidisciplinary tertiary care center. The research was approved by the University of Baskent Institutional Review Board and was conducted in compliance with principles of Helsinki declaration.

The data were collected by using three different forms between April 2016 and January 2016 through hospital-based cancer registry; 1) The Patient Information Form, 2) The Charlson Comorbidity Index (CCI), and 3) The Eastern Cooperative Oncology Group (ECOG) Performance Scale.

\section{The Patient Information Form}

This form includes 21 questions to define individual and medical characteristics of the women with OC such as patient age at diagnosis, educational level, occupation, marital status, family income, smoking history, alcohol use history, family history, distance of patient travel, residence, survival time information, clinic-pathological characteristics (stage, grade, cell subtype, recurrence, re- 
hospitalization and readmission, primary surgery, treatment modality, treatment toxicities, preoperative CA125, postoperative and intraoperative complications). Histology was classified based on the International Classification of Diseases for Oncology (ICD-O) as serous, mucinous, endometrioid, clear cell; and tumor grade as well differentiated, moderately differentiated or poorly differentiated. Stage categories were based on the International Federation of Gynecology and Obstetrics (FIGO) stages I, II III and IV. Survival time was calculated from date of diagnosis until death or censoring. The overall survival (OS) was defined as the time from first diagnosis to death or the date of last follow up. Disease-free survival (DFS) is the time elapsed from PE to first recurrence and OS is the time from PE to the last follow-up date or death. BMI values of patients were classified as underweight (BMI $<18.5 \mathrm{~kg} / \mathrm{m}^{2}$ ), normal (BMI 18.5 $24.9 \mathrm{~kg} / \mathrm{m}^{2}$ ), overweight (BMI $25-29.9 \mathrm{~kg} / \mathrm{m}^{2}$ ), and obese (BMI $\geq 30 \mathrm{~kg} / \mathrm{m}^{2}$ ) according to World Health Organization (WHO) criteria. ${ }^{13}$

\section{The Charlson Comorbidity Index (CCI)}

Comorbidity was measured for each patient using the Charlson Comorbidity Index (CCI), categorized as 0,1 , or $\geq 2$, with a higher score indicating a larger number or greater severity of comorbidities. ${ }^{14}$ The CCI, ranging from 0 to 29 , consists of a weighted sum of 17 major illnesses (e.g., myocardial infarction, stroke, diabetes, liver disease, dementia, renal disease). HT was included in the list of possible comorbid illnesses.

\section{European Cooperative Oncology Group (ECOG) Performance Scale}

This scale was developed by the Eastern Cooperative Oncology Group (ECOG) in 1982 to classify a patient according to their functional impairment, compare the effectiveness of therapies, and assess the prognosis of a patient (from 0 to 5, with 0 denoting perfect health and 5 death). ${ }^{15}$

\section{Statistical Analysis}

Descriptive statistical analyses were performed with SPSS version 18 (SPSS inc., Chicago, IL). Categorical variables were compared using Pear-

\begin{tabular}{|c|c|c|}
\hline Demographics & $\mathbf{n}$ & $\%$ \\
\hline \multicolumn{3}{|c|}{ Age at diagnosis (Mean: 56.4, range 20-80) } \\
\hline$<40$ & 16 & 14.3 \\
\hline $40-60$ & 61 & 54.3 \\
\hline$>60$ & 35 & 31.3 \\
\hline \multicolumn{3}{|l|}{ Education status } \\
\hline Primary school & 63 & 56.2 \\
\hline High school or higher & 49 & 43.8 \\
\hline \multicolumn{3}{|l|}{ Marital status } \\
\hline Married & 97 & 86.6 \\
\hline Single & 15 & 13.4 \\
\hline \multicolumn{3}{|l|}{ Employment status } \\
\hline Yes & 23 & 20.3 \\
\hline No & 89 & 79.7 \\
\hline \multicolumn{3}{|l|}{ Income status } \\
\hline Good & 8 & 7.1 \\
\hline Medium & 76 & 67.9 \\
\hline Poor & 28 & 25.0 \\
\hline \multicolumn{3}{|c|}{ Parity (Mean: 3.3, range 0-10) } \\
\hline 0 & 15 & 13.4 \\
\hline $1-3$ & 54 & 58.2 \\
\hline$\geq 4$ & 43 & 28.4 \\
\hline \multicolumn{3}{|l|}{ Region are of residence } \\
\hline Rural & 15 & 13.4 \\
\hline Urban & 97 & 86.6 \\
\hline \multicolumn{3}{|c|}{$\begin{array}{l}\text { Distance from residence to hospital, miles (Mean: 210, range } \\
0-750 \text { ) }\end{array}$} \\
\hline $0-12.49$ & 28 & 25.0 \\
\hline $12.5-49.9$ & 9 & 8.0 \\
\hline $50-249$ & 6 & 5.4 \\
\hline$\geq 250$ & 69 & 61.6 \\
\hline \multicolumn{3}{|l|}{ Smoking } \\
\hline Yes (>10 pack-days) & 30 & 26.8 \\
\hline No (Never) & 82 & 73.2 \\
\hline Total & 112 & 100.0 \\
\hline
\end{tabular}

son chi-square test and continuous variables using the Wilcoxon-Mann-Whitney and Kruskal-Wallis tests. Survival was estimated using the KaplanMeier method. Univariate and multivariate Cox Regression model (95\% CIs) were used to evaluate the effects of multiple prognostic factors on survival. ${ }^{16}$ The significance level was $\mathrm{p}<0.05$.

\section{RESULTS}

There were 112 patients who met inclusion criteria. The patients' general characteristics are shown in Table 1. The median age at diagnosis was 56.4 years + 11.3 (min: 20 - max: 80). Findings determined that $56.2 \%$ were primary school graduates, 


\begin{tabular}{|c|c|c|}
\hline Variables & $\mathbf{n}$ & $\%$ \\
\hline \multicolumn{3}{|c|}{ Menopausal status (Mean: 48.8, range 26-55 y) } \\
\hline Premenopausal & 34 & 30.4 \\
\hline Postmenopausal & 78 & 69.6 \\
\hline \multicolumn{3}{|l|}{ Type of menopausal } \\
\hline Natural & 73 & 65.2 \\
\hline Surgery & 39 & 34.8 \\
\hline \multicolumn{3}{|l|}{$\mathrm{BMl}$} \\
\hline Normal $(18.5-24.9 \mathrm{~kg} / \mathrm{m} 2)$ & 49 & 43.8 \\
\hline Overweight + Obese $(\geq 25 \mathrm{~kg} / \mathrm{m} 2)$ & 63 & 56.3 \\
\hline \multicolumn{3}{|l|}{ Caregiver support } \\
\hline Yes & 96 & 85.7 \\
\hline No & 16 & 14.3 \\
\hline \multicolumn{3}{|l|}{ Psychological support } \\
\hline Yes & 34 & 30.4 \\
\hline No & 78 & 69.6 \\
\hline \multicolumn{3}{|c|}{ Gynecological cancer in the family history } \\
\hline Yes & 13 & 11.6 \\
\hline No & 99 & 88.4 \\
\hline \multicolumn{3}{|l|}{ Cancer in the family history } \\
\hline Yes & 37 & 33.0 \\
\hline No & 75 & 67.0 \\
\hline \multicolumn{3}{|l|}{ Previous surgery history } \\
\hline Yes & 54 & 48.2 \\
\hline No & 58 & 51.8 \\
\hline \multicolumn{3}{|l|}{$\mathrm{CCl}$} \\
\hline 0 & 40 & 35.7 \\
\hline 1 & 54 & 48.2 \\
\hline$\geq 2$ & 18 & 16.1 \\
\hline Total & 112 & 100.0 \\
\hline
\end{tabular}

$79.7 \%$ were housewives, $86.6 \%$ were married, $67.9 \%$ had their income equal to expenditure, and $86.6 \%$ were urban dwellers. The mean parity was 3.35 , ranging from 0 to 10 . All of the women had health insurance, $73.2 \%$ did not smoke $(99.5 \%$ did not drink alcohol). Distance from residence to center, miles (range) was 210 $\pm 10.2(0-750)$ (Table $1)$.

Seventy percent of women were diagnosed during menopause (the rate of surgically induced menopause was $34.8 \%$ ). More than half of women were obese $(56.3 \%)$. The majority of women had a caregiver $(85.7 \%)$. One in three received psychological support for their illnesses. Thirty-three percent of women had cancer stories in their families and

\begin{tabular}{|c|c|c|}
\hline Variables & $\mathbf{n}$ & $\%$ \\
\hline \multicolumn{3}{|c|}{ Initial symptoms at first admission } \\
\hline Abdominal-pelvic pain & 22 & 19.6 \\
\hline Vaginal bleeding-irregul & ual cycle 40 & 35.7 \\
\hline Abdominal distension & 50 & 44.6 \\
\hline \multicolumn{3}{|l|}{ Stage } \\
\hline $1-2$ & 30 & 17.8 \\
\hline 3-4 & 92 & 82.2 \\
\hline \multicolumn{3}{|l|}{ Grade } \\
\hline $1 / 2$ & 38 & 33.9 \\
\hline$\geq 3$ & 72 & 66.1 \\
\hline \multicolumn{3}{|l|}{ Subtype } \\
\hline Serous & 85 & 75.9 \\
\hline Endometrioid & 16 & 13.2 \\
\hline Mucinous & 6 & 6.4 \\
\hline Clear cell & 5 & 4.5 \\
\hline \multicolumn{3}{|c|}{ Primary surgery } \\
\hline \multicolumn{2}{|c|}{ USO + BPPLND + Omentectomy 9} & 8.0 \\
\hline TAHBSO & 12 & 10.7 \\
\hline $\begin{array}{l}\text { TAHBSO + BPPLND + } \\
\text { Omentectomy }\end{array}$ & 91 & 81.3 \\
\hline \multicolumn{3}{|l|}{ Other treatments } \\
\hline СТ & 88 & 78.6 \\
\hline RT & 23 & 20.5 \\
\hline $\mathrm{CT}+\mathrm{RT}$ & 11 & 9.9 \\
\hline \multicolumn{3}{|l|}{$\mathrm{CT}+\mathrm{RT}$ Toxicities } \\
\hline Yes & 96 & 85.7 \\
\hline No & 33 & 29.4 \\
\hline \multicolumn{3}{|l|}{ ECOG } \\
\hline $0-1$ & 74 & 66.1 \\
\hline $2-3$ & 38 & 33.9 \\
\hline \multicolumn{3}{|l|}{ Preop CA12-5 } \\
\hline $35-500$ & 85 & 75.9 \\
\hline$\geq 500$ & 27 & 24.1 \\
\hline \multicolumn{3}{|l|}{ Recurrence } \\
\hline 1 & 71 & 63.4 \\
\hline$>1$ & 41 & 36.6 \\
\hline \multicolumn{3}{|l|}{ Postoperative complication } \\
\hline Yes & 21 & 18.7 \\
\hline No & 91 & 81.3 \\
\hline \multicolumn{3}{|l|}{ Intraoperative complication } \\
\hline Yes & 8 & 6.2 \\
\hline No & 104 & 92.8 \\
\hline \multicolumn{3}{|c|}{ Unplanned readmission at least one (hospitalized -76\%) } \\
\hline Yes & 69 & 61.6 \\
\hline No & 43 & 38.4 \\
\hline \multicolumn{3}{|c|}{$\begin{array}{l}\text { Abbreviations: CA125: Serum cancer antigen } 125 \text {, CT: Chemothera- } \\
\text { py, RT: Radiotherapy, USO: Unilateral Salpingo-Oophorectomy, TAH- } \\
\text { BASO: Total Abdominal Hysterectomy and Bilateral Salpingo-Oopho- } \\
\text { rectomy, BPPLND: Bilateral pelvic and paraaortic lymphadenectomy }\end{array}$} \\
\hline
\end{tabular}




\begin{tabular}{|lll|}
\hline \multicolumn{3}{|l|}{ Table 4. Distributions of OS and DFS scores } \\
\hline Years (y) & $\begin{array}{l}\text { Overall survival } \\
\text { (OS) }\end{array}$ & $\begin{array}{l}\text { Disease-free survival } \\
\text { (DFS) }\end{array}$ \\
\hline 1 y & $94.3 \%$ & $68.7 \%$ \\
2 y & $83.4 \%$ & $33.4 \%$ \\
$3 y$ & $66.4 \%$ & $15.3 \%$ \\
$4 y$ & $54.7 \%$ & - \\
$5 y$ & $42.8 \%$ & - \\
Median & 60.5 months & 18.3 months \\
(\%95 GA) & (range 43-68) & (range 10-27) \\
& (95\%Cl) & (95\%Cl) \\
\hline
\end{tabular}

eleven-one percent of women had gynecological cancer stories in their families. Among patients with OC, $35.7 \%$ had an CCI- 0 , and $48.2 \%$ had an CCI- 1, $(28.2 \%)$ had an CCI -2 (16.1\%), had an CCI-3 (8.5\%) (Hypertension also has been identified as $48.6 \%$ ). \%48.2 patients had previous surgery (Cesarean section 29.5\%, cholecystectomy $14.3 \%$, and thyroidectomy 6.3\%) (Table 2).

Primary surgery was performed on 112 patients during this 5-year period (secondary cytoreductive surgery was performed on all of the patients and nearly half of the patients underwent tertiary cytroductive surgery) and was removed all visible tumor. 91 patients; TAHBSO + BPPLND + omentec- tomy, 12 patients; only TAHBSO, 9 patients; USO + BPPLND + omentectomy (as additional surgery; 41 patients appendectomy; 8 patients cholecystectomy; 12 patients splenectomy; 6 patients colon resection + colostomy. Hospital length of stay after surgery was $13.14 \pm 4.64$. Postoperative complications were seen in 21 patients $(18.7 \%$ ) (within 4 weeks after surgery). These complications were fewer $(18.6 \%)$, wound evisceration $(4.5 \%)$, respiratory complication $(3.3 \%)$, ileus $(11.3 \%)$, DVT (16.3\%), lymphocele (3.2\%). Rate of intraoperative complication was $8.4 \%$ (defects in the bowel serosa during surgery). Readmission rate was $61.6 \%$. Patterns of unplanned readmission in patients were deep vein thrombosis-DVT (19.6\%), pyrexia $(60.7 \%)$, acute abdomen $(29.6 \%)$, genital tract infection $(22.3 \%)$, pain and weakness $(56.3 \%)$, dyspnea $(7.4 \%)$ and ileus $(22.3 \%)$ (Table 3$)$.

Most $(82.2 \%)$ had stage III or IV cancer (all of them were epithelial type OC). More than half the cancers $(75.9 \%)$ were serous subtype and $66.1 \%$ were high-grade $(\geq 3)$. All of patients underwent primary surgery (The mean operative time was 120 minutes). $85.7 \%$ of patients received CT (median cure was $6.2+3.3$ ) (platinum-taxane -paclitaxel+carboplatin $88.3 \%$, cisplatin/ gemcitabine $8 \%$ and doxorubicin + carboplatin 6\%) and only $20.5 \%$ RT. ECOG performance status was " 0 1 ” $(66.1 \%)$, “ $\geq 2$ " (33.9\%) in patients' last hospitalizations (Table 3). Hematologic and non-hemato-

\begin{tabular}{|c|c|c|c|}
\hline Variables & HR & $\% 95 \mathrm{Cl}$ & $\mathbf{P}$ \\
\hline Age at diagnosis ( $\leq 40 \mathrm{y} v \mathrm{~s}>40 \mathrm{y}$ ) & 1.78 & $1.20-1.85$ & 0.015 \\
\hline Stage (III-IV vs I-II) & 1.38 & $1.28-2.91$ & 0.001 \\
\hline Recurrence (1 vs >1) & 1.64 & $1.50-1.93$ & 0.001 \\
\hline BMI $\left(\geq 25\right.$ kg/m² vs $\left.<25 \mathrm{~kg} / \mathrm{m}^{2}\right)$ & 1.22 & $1.15-1.32$ & 0.004 \\
\hline Subtype (serous vs others) & 1.07 & $1.10-1.28$ & 0.001 \\
\hline Menopausal status (pre vs post) & 1.50 & $1.14-1.61$ & 0.017 \\
\hline Tumor grade (1-2 vs $\geq 3)$ & 1.03 & $1.23-2.39$ & 0.001 \\
\hline Cancer in family history (yes vs no) & 1.52 & $1.11-2.15$ & 0.032 \\
\hline ECOG (0-1 vs $\geq 2)$ & 1.10 & $1.00-1.35$ & 0.002 \\
\hline Comorbidity (0-1 vs $\geq 2$ ) & 1.31 & $1.20-1.46$ & 0.001 \\
\hline Residence distance ( $\leq 50$ miles vs $>50$ miles) & 1.29 & $1.02-1.33$ & 0.021 \\
\hline
\end{tabular}


International Journal of Hematology and Oncology

\begin{tabular}{|c|c|c|c|}
\hline Variables & HR & $\% 95 \mathrm{Cl}$ & $\mathbf{P}$ \\
\hline Age at diagnosis ( $\leq 40 \mathrm{y}$ vs $>40 \mathrm{y})$ & 1.37 & $1.26-1.46$ & 0.009 \\
\hline Stage (III-IV vs I-II) & 2.01 & $1.02-2.84$ & 0.003 \\
\hline Recurrence (1 vs >1) & 1.84 & $1.05-1.33$ & 0.001 \\
\hline BMI $\left(\geq 25 \mathrm{~kg} / \mathrm{m}^{2}\right.$ vs $\left.<25 \mathrm{~kg} / \mathrm{m}^{2}\right)$ & 1.15 & $1.17-1.29$ & 0.005 \\
\hline Subtype (serous vs others) & 1.23 & $1.16-1.30$ & 0.001 \\
\hline Menopausal status (pre vs post) & 1.32 & $1.28-1.87$ & 0.010 \\
\hline Tumor grade (1-2 vs $\geq 3)$ & 1.16 & $1.43-2.30$ & 0.007 \\
\hline Higher comorbidity (0-1 vs $\geq 2$ ) & 1.65 & $1.11-2.13$ & 0.002 \\
\hline Residence distance ( $\leq 50$ miles vs $>50$ miles) & 1.36 & $1.26-1.43$ & 0.009 \\
\hline
\end{tabular}

logic toxicity of the CT and RT comprised anemia (29.7\%), neutropenia (28.6\%), thrombocytopenia (26.3\%), pain (33.4\%), alopecia (48.9), diarrhea $(18.4 \%)$, nausea/ vomiting $(38.4 \%)$, and oral mucositis (13.7\%). No patient was lost to follow-up.

The OS for patients was 60.5 months and the median DFS rate was 18.3 months. The 1-year survival rate was $94.3 \%$, 2-year survival rate was $83.4 \%$, 3-year $66.4 \%$, 4-year $54.7 \%$, and 5- year $42.8 \%$. DFS scores were 1-year 68.7\%, 2-year 33.4\%, and 3-year $15.3 \%$ (Table 4). Univariate model revealed that the menopausal status, age at diagnosis, the FIGO stage, grade, histological type, performance status, recurrence, BMI, residence distance, cancer in the family history and the comorbidity were related with OS significantly (Table 5). On multivariate analysis, advanced age was significantly associated with worse OS (HR, 1.3 [95\% CI, 1.2-1.4] than younger women. Mucinous, endometrioid and clear cell subtypes were associated with worse OS than serous cancers (HR, 1.2 [95\% CI, 1.1-1.3]). Postmenopausal period (HR, 1.2 [95\% CI, 1.2-1.8), obesity (HR, 1.1 [95\% CI, 1.1-1.2), presence of recurrence (HR, 1.4 [95\% CI, 1.0-1.3), and higher comorbidity scores $(\geq 2)$, higher grade (HR, 1.1 [95\% CI, 1.4-2.3) and stage (HR, 2.0 [95\% CI, 1.0-2.8) had significantly poorer OS rates (HR, 1.6 [95\% CI, 1.1-2.1). Regional-remote residence were also associated with poorer OS (HR, 1.3 [95\% CI, 1.2-1.4]) (Table 6).
Compared to good prognosis women, poor prognosis women were less educated, and income level, had before surgery, high toxicity, and re-hospitalization. However, there was no significant difference in OS between the groups ( $p>0.05)$. There were no major differences in distribution of other prognostic factors $(\mathrm{p}>0.05)$.

\section{DISCUSSION}

OC is often called the silent killer; women often ignore early signs because there are no clearly identifiable initial symptoms often confused with complaints of common benign gastrointestinal disorders such as abdominal distension and pain due to acidity. Because of diagnostic challenges only one fifth of OC patients are detected at the localized stage. Frequently, women are medically managed for indigestion or other complaints without having a pelvic examination, thus significant delays before diagnosis are very common. ${ }^{4,5}$

In our study abdominal distension was seen in $44.6 \%$ of patients, which was followed by abdominal/pelvic pain with a rate of $19.6 \%$, and vaginal bleeding/irregular menstrual cycles was found in $35.7 \%$. In accordance with our study Oge et $\mathrm{al}^{7}$ also reported abdominal swelling as the most common complaint (59.1\%), and the second most frequent complaint was reported as abdominal pain 
(20.8\%). Physician and nurses recommendations regarding alarming symptoms and screening programs in this population are a vital investment on survival for OC. In addition there is a real need for new, more effective screening options for women with OC.

Cancer statistics often use 5-year OS rate to present a better idea of the longer-term outlook for people with cancer. ${ }^{5}$ We found that the OS for OC was $94.3 \%, 66.4 \%$, and $42.8 \%$ at 1,3 , and 5 years, respectively. Also, the median OS time was 60.5 months. The slope of decline in OS was reduced during the first years after diagnosis. Most patients diagnosed with OC, survival is theorized to be $100 \%$, who are still alive after 5-years, are presumably living with the disease rather than living disease-free. ${ }^{5}$ Our analysis demonstrated that the DFS was 18.3 months (10-27). The Surveillance, Epidemiology and End Results-SEER database from 1995 to 2007 with epithelial OC who were actively followed-up and age 20 years or older were included for analyzing OS in the United States (40.692 patients) and OS was $65 \%, 44 \%$, and $36 \%$ at 2, 5, and 10 years, respectively. ${ }^{10}$ Bailey et al. ${ }^{17}$ evaluated the 5-year outcome of women $(n=361)$ with advanced OC in the South West of England as stage III was $16 \%$ and with stage IV was $10 \%$. Recent prospective and randomized trials demonstrated that patients with advanced OC $(n=718)$ from 1998 through 2006 at 59 institutions in Canada have similar survival (OS: 29-30 months, DFS: 12 months). ${ }^{18}$ In a study the median DFS and OS for patients with OC were 35.0 months and 54.0 months respectively. ${ }^{19}$ In different study done by Anuradha et al in 2014, 1192 Australian women diagnosed with invasive epithelial OC in 2005 were identified through state-based cancer registries and the 5-year OS was 53\%. ${ }^{20}$ A Swedish study published in 2009 of 682 patients with epithelial OC found a 10 -year relative survival rate of $38.4 \%$, the median OS time was 81 months (52-109 months) in OC patients. ${ }^{6}$ Larger population-based analyses of 10-year OS in OC have not been published in the Turkish populations. In a study performed in Turkey, according to the surgical stages I, II, III and IV median survival was 78.5 months, 60.1 months, 33.9 months and 16.1 months respectively and significantly different. ${ }^{7}$ In a study by Karaca ${ }^{21}$ study, a number of 13.590 women (from 9 nationwide cancer registry centers) were evaluated who got gynecological cancer diagnosis (31.2\% OC) in Turkey between 2004 and 2011, overall 5-year observed OC survival rate was $46 \%$. Buldanlı et al reported that OS was $51.6 \%$ in Western Turkey. When we compare the all of results with national or international studies, the 5-year survival rate in our study did not differ from the 5-year survival published from the general population.

Previous studies have shown that the survival of $\mathrm{OC}$ is affected by personal history, and genetic factors including low socioeconomic status, and life style. ${ }^{18,22-26}$ We scrutinized the analyzing related to various prognostic factors for OC. In the present study younger women, those diagnosed before the age of 40, had significantly better survival after five years than women diagnosed at older ages $(\mathrm{p}<0.05)$. Older age at diagnosis was often associated with comorbidities and functional deficits that impact their survival. Gershenson et $\mathrm{al}^{27}$ reported on a cohort of 112 patients with stage II-IV low-grade serous carcinoma from M.D. Anderson Cancer Center in 2006, and noted age older than 45 years at diagnosis was associated with longer survival. Some studies reported that increasing age was most strongly associated with poor survival. ${ }^{910,18-20,22}$ However, in the other studies of Oge et $\mathrm{al}^{7}$ and Buldanls et $\mathrm{al}^{11}$ revealed that age was not was not effected by the age of the patients in OC.

Recently, treatments for cancer has resulted in increasingly complex care patterns and individualization of care by multidisciplinary teams. Lack of access to a qualified region for proper oncology center may impact outcome and contribute to disparities in early stage cancer. Access to on site appropriately qualified healthcare center is essential to decrease distance barriers and to improve survival. ${ }^{22}$ Conversely, Shylasree et $a^{28}$ analyzed that there were no significant differences survival between women managed in the cancer center and those managed in the peripheral units. In our study, the patients are referred to the study hospital because they do not have a high-quality healthcare setting in the periphery. In our study, patients who traveled less than 50 miles for their cancer care 
were more often favorable prognosis than patients who had traveled more than 50 miles $(\mathrm{p}<0.05)$. Similarly, Anuradha et $\mathrm{a}^{20}$ reported that regional distance (HR, 1.2 [95\% CI, 1.0-1.4]) was also associated with poorer OS. A Cochrane Review by Woo et $\mathrm{al}^{24}$ in 2012 identified five studies (total 62.987 women with gynecological cancer), and concluded that women with advanced OC may have improved outcomes if treated in specialist centers (in a twofold). In the light of this information, these results would be important for future studies to assess the survival associated with centralization of this cancer care.

Beyond some demographic and medical features, relatively little is known about reproductive factors that may influence survival after OC diagnosis. ${ }^{5}$ In our study revealed women with postmenopausal had poorer OS scores than women with premenopausal $(\mathrm{p}<0.05)$. OC may be diagnosed earlier in premenopausal women than in postmenopausal women, because one major symptom used to identify OC is a change in menstruation. Premenopausal women are also more likely to develop types of tumors that are easier to detect and therefore, the chances of survival are higher. ${ }^{18,22,23}$ Our results were similar previously reported in the literature but inconsistent with a population-based cohort study of Australian women that found no association. $^{20}$

Comorbidities such as diabetes, heart disease and hypertension may impact this treatment disparity. The majority of studies show that comorbidities were found as the prognostic factors that influence the survival. ${ }^{6,18,28,29}$ In a different study ${ }^{20}$, a high comorbidity score of $\geq 2$ was associated with a decreased OS rates (HR, 1.5 [95\% CI, 1.1-2.1]). When we performed our analyses, we either did found a relationship, higher comorbidity score was found to have poorer OS. The results of our study are consistent with the literature.

Due to the prolonged OC course, obesity as potentially modifiable risk factors may alter the survival. Suh et $\mathrm{al}^{30}$ reported that survival of $\mathrm{OC}$ was more influenced by the obese environment. In a different study $^{25}$, obesity was found significant predictors of OS. In this study similarly, overweight/obesity defined as a $B M I \geq 25 \mathrm{~kg} / \mathrm{m}^{2}$, demonstrated associa- tion with worse OS. The role of obesity on survival both in the literature and in our results provides evidence for women diagnosed with OC. Therefore, avoiding obesity in relation to treatment practices is the main strategy to improve the survival, as the health provider is expected to address obesity factors in developing a plan of care.

Some types of OC have a more favorable prognosis. As reported in several studies, mucinous or clear-cell histology was associated with a worse OS compared with serous carcinomas. ${ }^{6,9,11,18,20}$ Similar to others, we found that women with clear cell, endrometrioid and mucinous type had the poorest survival, possibly reflecting aggressive tumor biology or less sensitivity to routinely used chemotherapy. However, Benvito et ${ }^{23}$ and Shysasree et $\mathrm{al}^{28}$ were not found of survival differences between subtypes and survival. Akhtar-Danesh et $\mathrm{al}^{22}$ reported that the worst survival observed for serous tumors.

In our study, low-grade tumor was associated with a more favorable prognosis than high-grade $(\mathrm{p}<$ 0.05 ). Bodurka et $\mathrm{al}^{31}$ analyzed 378 women with low-grade tumors had significantly longer median DFS values than those with high-grade carcinomas (45.0 vs 19.8 months; $\mathrm{p}<0.001$ ). Similarly, other studies found that higher grade remained significantly associated with survival. ${ }^{6,9,11,17,18,20,23}$ A multivariate analysis showed that, for $\mathrm{OC}$, the histological grade was a significant prognostic factor for DFS but not for OS. ${ }^{19}$ As reported in several studies, grade as important prognostic factors is still controversial.

Matz et $\mathrm{al}^{8}$ analyzed data from 60 countries for 695.932 women with OC during 2005-2009. 5-year OS ranged from 40 to $70 \%$ for type I localized epithelial OC, for type II advanced epithelial tumors was much lower (20-45\%). In a different study, the survival rates were higher for women with earlier stage cancers. ${ }^{9}$ We found that stage was the most important prognostic factor with regard to survival. Consistent with other work, we also revealed that high stage had significantly effect on OS ( $p<0.05)$. In contrast, Shylasree et $\mathrm{al}^{28}$ analyzed the outcomes of 250 women with OC and there were no significant differences regarding stage between OS. 
Currently, there is no recommendation for routine OC screening from any national organization. Routinely checking markers and CT scans do not result in early detection or longer survival in either the general or high-risk populations. ${ }^{5}$ An elevated CA125 was not determinant factors of OS in our study ( $p>0.05$ ) in our study. Similar to the study of Whoo et $\mathrm{al}^{24} \mathrm{CA} 125$ level was not influence on OS for OC. However we found that presence of recurrence had significant effect on survival in OC ( $p>0.05)$. As mentioned in several studies the patients with recurrent had significantly shorter survival. ${ }^{24,29}$

\section{Conclusion}

In the result of this study, the 5-year survival for OC was $42.8 \%$. The time of OS for patients was 60.5 months and the median DFS rate was 18.3 months, clearly reinforcing the need for prevention, early detection and better treatments. Advanced age, subtype, recurrence, comorbidities, obesity, distance to residence, postmenopausal period, stage and grade were also associated with OS. Ideally, any prospective studies should be performed on large number of patients to accurately establish whether geographic and socioeconomic differences, and medical features relate to survival. Until better screening tools are available, patient education and close follow-up remain the most important intervention for prevention of OC. Also, individualized healthcare may be able to determinant impact on survival for these women.

\section{Limitations}

All of data from were a single hospital registry, thus not representative of the general population. However, this study was a maiden attempt to reveal that substantial prognostic factors of OC. Also, none of the studies looked at risk of some social factors such as regional distance or caregiver support, which would be important to those commissioning healthcare services.

\section{REFERENCES}

1. Ferlay J, Shin HR, Bray F, et al. Estimates of worldwide burden of cancer in 2008: GLOBOCAN 2008. International journal of cancer. Int J Cancer 127: 2893-28917, 2010.

2. Sankaranarayanan R, Ferlay J. Worldwide burden of gynecological cancer: the size of the problem. Best Prac Res Clin Obstet Gynaecol 20: 207-225, 2006.

3. Republic of Turkey Ministry of Health (2009-2015) Department of Cancer Control National Cancer Program, Ministry Publication No: 760.

4. Chan JK, Kapp DS, Shin JY, et al. Influence of the gynecologic oncologist on the survival of ovarian cancer patients. Obstet Gynecol 109: 1342-1350, 2007.

5. Chabner BA, Lynch TJ, Longo DL. Ovarian Cancer. Harrison's Manual of Oncology. 2nd Ed., New York, McGraw-Hill 2014: 485-502.

6. Akeson M, Jakobsen AM, Zetterqvist BM, et al. A populationbased 5-year cohort study including all cases of epithelial ovarian cancer in western Sweden: 10-year survival and prognostic factors. Int J Gynecol Cancer 19: 116 -123, 2009.

7. Oge T, Ozalp S, Yalcin OT. Prognostic Factors In Epithelial Ovarian Carcinoma: A Reference Institution Experience. J Turk Soc Obstet Gynecol 8: 51-56, 2011.

8. Matz M, Coleman MP, Carreira H, et al. Worldwide comparison of ovarian cancer survival: Histological group and stage at diagnosis (CONCORD-2). Gynecol Oncol 144: 396-404, 2017.

9. Winter WE III, Maxwell GL, Tian C, et al. Prognostic factors for stage III epithelial ovarian cancer: a Gynecologic Oncology Group Study. J Clin Oncol 25: 3621-3627, 2007.

10. Lauren AB, Bin H, Rachel WM, et al. Ten-Year Relative Survival for Epithelial Ovarian Cancer. Obstet Gynecol 120: 612618, 2012.

11. Buldanli N, Uslu T, Saygili U, et al. Jinekolojik Tümörlerde Sagkalim ve Buna Etki Eden Faktörler: DEJOG Serisi. TJOD 9: 6774, 2006.

12. Crawford R, Greenberg D. Improvements in survival of gynecological cancer in the Anglia region of England: are these an effect of centralization of care and use of multidisciplinary management? BJOG 119: 160-165, 2012.

13. Charlson ME, Pompei P, Ales KL, et al. A new method of classifying prognostic comorbidity in longitudinal studies: development and validation. J Chronic Dis 40: 373-83, 1987.

14. WHO (World Health Organization). Obesity: Preventing and managing the global epidemic. Report of a WHO consultation. World Health Organization technical report series. Report No: 894, Geneva 2000.

15. Oken M, Creech R, Tormey D, et al. Toxicity and response criteria of the Eastern Cooperative Oncology Group. Am J Clin Oncol 5: 649-655, 1982. 
16. Cox DR. Regression models and life-tables. JR Stat Soc 34: 187-220, 1972.

17. Bailey J, Murdoch J, Anderson R, et al. Stage III and IV ovarian cancer in the South West of England: five-year outcome analysis for cases treated in 1998. Int J Gynecol Cancer 16: 25-29, 2006.

18. Vergote I, Trope CG, Amant F, et al. Neoadjuvant chemotherapy or primary surgery in stage IIIC or IV ovarian cancer. N Engl J Med 363: 943-953, 2010.

19. Chen M, Jin Y, Yalan B, et al. A survival analysis comparing women with ovarian low-grade serous carcinoma to those with high-grade histology. Onco Targets Ther 7: 1891-1899, 2014.

20. Anuradha S, Web PM, Blomfield P, et al. Survival of Australian women with invasive epithelial ovarian cancer: a populationbased study. Med J Aust 201: 283-288, 2014.

21. Karaca MZ. Gynecological cancer trends and 5 -year survival in Turkey: Analysis ff 13.590 cancer patients. ESGO-eAcademy 0761. Abstract Oct 24, 2015.

22. Akhtar-Danesh N, Elit L, Lytwyn A. Temporal trends in the relative survival among patients diagnosed with ovarian cancer in Canada 1992-2005: A population-based study. Gynecol Oncol 123: 192-195, 2011

23. Benito V. What types of gynecological cancer are expected in women under the age of 40 ? Long term follow-up study on 461 patients. ESGO eAcademy Abstract No: 37857, October 2013.

24. Woo YL, Kyrgiou M, Bryant A, et al. Centralization of services for gynecological cancer. Cochrane Database of Systematic Reviews 2012, Issue 3. Art. No: CD007945.

25. Previs RA, Kilgore J, Craven R, et al. Obesity is associated with worse overall survival in women with low-grade papillary serous epithelial ovarian cancer. Int J Gynecol Cancer 24: 670-675, 2014.
26. Tracey E, Hacker NF, Young J, Armstrong BK. Effects of access to and treatment in specialist facilities on survival from epithelial ovarian cancer in Australian women: a data linkage study. Onco Targets Ther 7: 1891-1899, 2014.

27. Gershenson D, Sun C, Lu K, et al. Clinical behavior of stage II-IV low-grade serous carcinoma of the ovary. Obstet Gynecol 108: 361-368, 2006.

28. Shylasree TS, Howells RE, Lim K, et al. Survival in ovarian cancer in Wales: Prior to introduction of all Wales guidelines. Int $\mathrm{J}$ Gynecol Cancer 16: 1770-1776, 2006.

29. Chi DS, Eisenhauer EL, Zivanovic O, et al. Improved progression-free and overall survival in advanced ovarian cancer as a result of a change in surgical paradigm. Gynecol Oncol 114: 26-31, 2009.

30. Suh DH, Kim HS, Chung HH, et al. Body mass index and survival in patients with epithelial ovarian cancer. J Obstet Gynaecol Res 38: 70-76, 2012.

31. Bodurka DC, Deavers MT, Tian C, et al. Reclassification of serous ovarian carcinoma by a 2-tier system: a Gynecologic Oncology Group Study. Cancer 118: 3087-3094, 2012.

\section{Correspondence:}

Dr. Gül PINAR

318. Cadde

No: $11 / 2$

CANKAYA / ANKARA

e-meail: gpinar_1@hotmail.com 